\title{
USING SORBENTS FOR OIL SPILL CLEAN-UP IN PORTS AND COASTAL AREAS
}

\author{
Włodzimierz Kończewicz, Sylwia Polasz, Kinga Rogowska \\ Gdynia Maritime University, Faculty of Marine Engineering \\ Department of Marine Maintenance \\ Morska Street 81-87, 81-225 Gdynia, Poland \\ tel.: +4858 5586323, +4858 5586564, fax: +48585586432 \\ e-mail:w.konczewicz@wm.umg.edu.,s.polasz@wm.umg.edu.pl \\ kinga.poland@gmail.com
}

\begin{abstract}
Petroleum substances are a mixture of many hydrocarbons of various structures; some of them are toxic for marine organisms. In case of pollution of the aquatic environment, these compounds may enter seawater organisms and adversely affect gas exchange and inhibit photosynthesis. Therefore, it is important to take measures to reduce the emissions of these compounds into the aquatic environment and quickly to remove possible spills of uncontrolled pollution. Sorbents are materials that soak up oil from water. They are best suited for the absorption of oil - derived substances. They are used to absorb leaks in open and closed tanks, particularly in hard - to-reach places. Sorbents can be natural organic, natural inorganic or synthetic. Natural sorbents are divided to organic materials such as peat moss or wood products, and inorganic materials such as vermiculite or clay. Sorbents are available in a loose form, which includes granules, powder, chunks and cubes. Synthetic sorbents are used to wipe other oil spill recovery equipment such as skimmers and booms after a spill clean-up operation. The thesis deals with the issues related to the analysis of the possibility of using sorbents to combat oil pollution in port and coastal areas. The article discusses the types of pollution occurring in coastal waters, as well as the types of sorbents used and the forces and measures to combat pollution. The characteristic features of sorbents are rate of absorption and adsorption, oil retention and ease of application. Absorption tests were carried out and the best sorbents for combating oil pollution were selected.
\end{abstract}

Keywords: materials engineering, maritime engineering, fuel, oils \& lubrication

\section{Introduction}

The marine environment is highly vulnerable to pollution from maritime transport and to a lesser extent from factories located directly by the sea. The direct impact of shipping on marine fauna and flora is limited primarily by the use of new technologies that limit the emission of air pollutants, control of proceedings with ballast waters, sewage and sediments. In a situation of continuous risk of occurring marine disasters, it is important to position the readiness for quick and effective response to oil-related pollutants. Environmental protection is one of the main priorities of economic development. Human activities have a negative impact on air, soil and water purity. Sorbents are used to neutralize the danger of petroleum derivatives resulting from emergency situations.

\section{The experimental research methodology}

Eighteen different sorbents were used for the absorbency tests:

a) two natural - Ecobark and Spill - Sorb,

b) six minerals - Vermiculite with three granulation, Damsorb, Ikasorb, Halosorb, Absonet Multisorb and Absonet Water Tolsa,

c) four synthetic - a nonwoven sorbent with three different granulations, polypropylene wadding, heavy polyurethane, cellulose -hydrocarbonate. 
The absorbency of the ground tire and powdered coal was also checked. Mazut and three types of oil were used, namely:

a) MARINOL RG 1240 fresh oil,

b) used oil MARINOL RG 1240, previously used in the engine 3 AL 25/30.

In Figs. 1-4 are presented microscopic photographs of selected sorbents, which were used for testing.

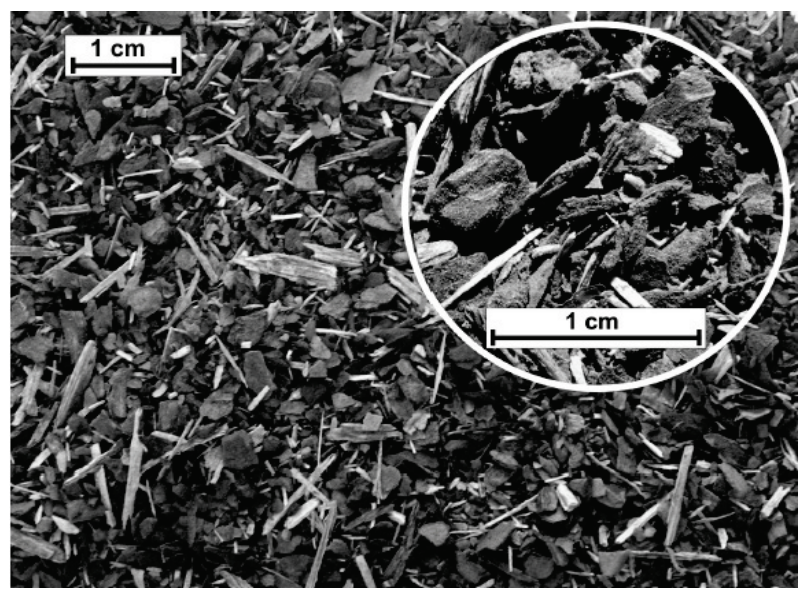

Fig. 1. Ecobark

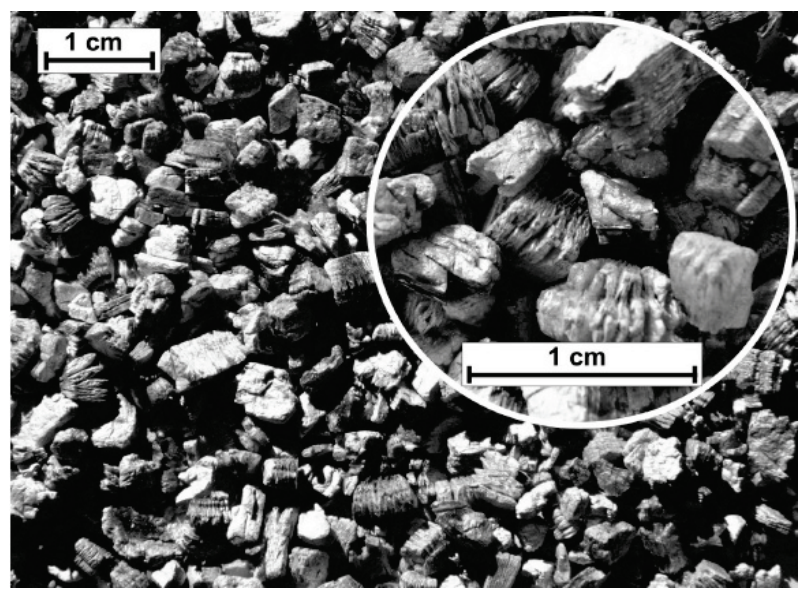

Fig. 3. Vermiculite - maxi

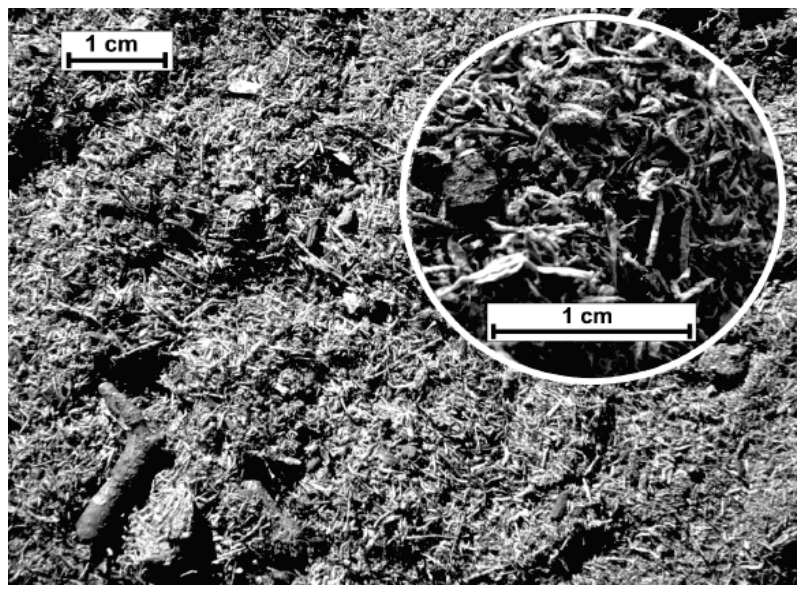

Fig. 2. Spill-sorb

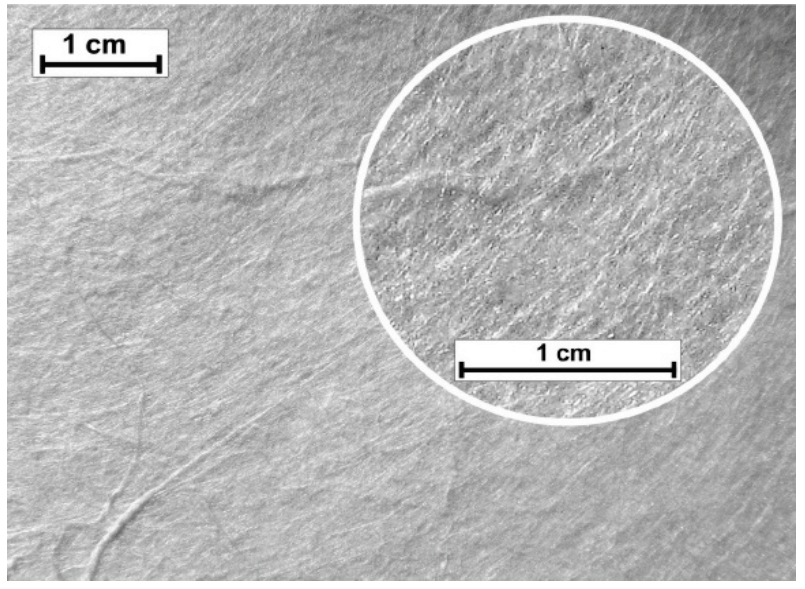

Fig. 4. Sorbent nonwoven WS 0.41/0.46

The tests were carried out in transparent containers in a cubic form, made Plexiglass $100 \times 100$ $\times 100 \mathrm{~mm}$ and plastic cups with a height $100 \mathrm{~mm}$. Tab. 1 shows the typical values obtained with the normal production batch tolerance for MARINOL RG 1240.

Tab. 1. Properties of MARINOL RG 1240 oil for day 03.03.2019

\begin{tabular}{|c|l|l|c|c|}
\hline No. & \multicolumn{1}{|c|}{ Requirements } & \multicolumn{1}{|c|}{ Test methods by } & Unit & Value \\
\hline 1. & Kinematic viscosity at $100^{\circ} \mathrm{C}$ & ASTM D-445 & $\mathrm{mm}^{2} / \mathrm{s}$ & 14.3 \\
\hline 2. & The flow temperature & ASTM D-5950 & ${ }^{\circ} \mathrm{C}$ & -21 \\
\hline 3. & Flash - point & PN-EN ISO 2592 & ${ }^{\circ} \mathrm{C}$ & 26 \\
\hline 4. & A basic number & ASTM D-2896 & $\mathrm{mgKOH} / \mathrm{g}$ & 12.8 \\
\hline 5. & Viscosity index & ASTM D-2270 & - & 98 \\
\hline
\end{tabular}

$100 \mathrm{ml}$ of a spill repelling substance and $45 \mathrm{ml}$ of loose sorbents was used in each trial, where the sorbents absorbency was checked. In case of synthetic sorbents, the amounts of sorption 
materials have been adapted to the dimensions of plastic cups - the sorbent nonwoven has been cut into wheels with a diameter of $50 \mathrm{~mm}$. Measurements were made at 300,600 and 900 seconds for each sorbent. Fig. 5 shows the absorption process.

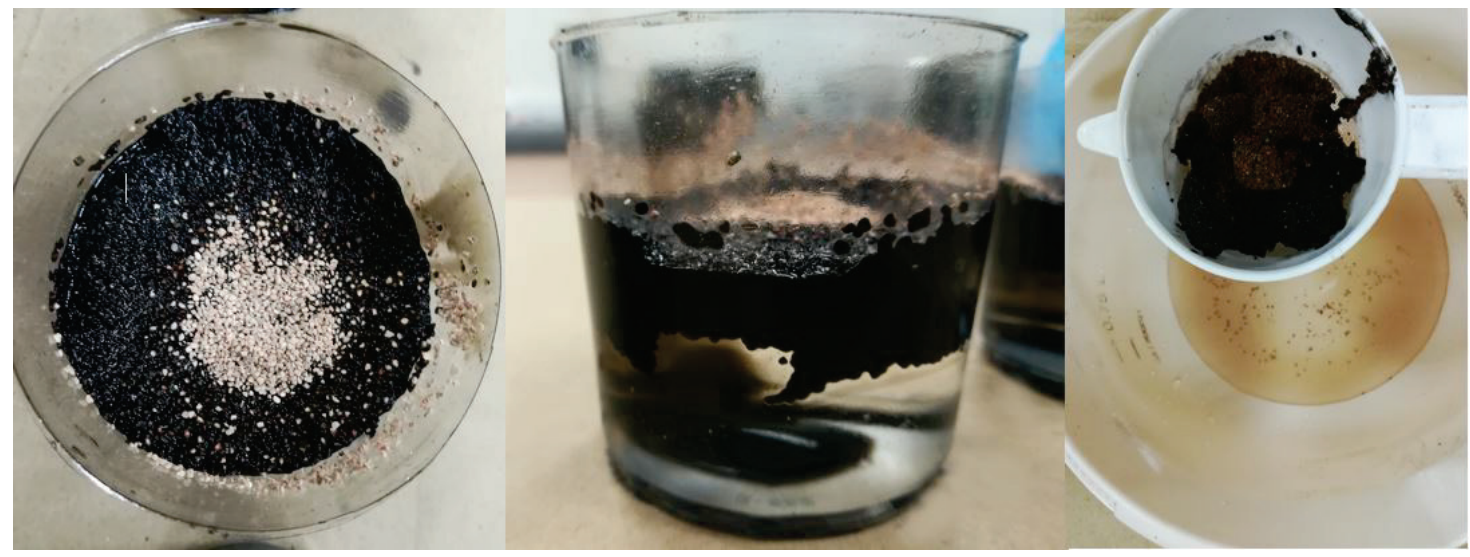

Fig. 5. Damsorb - mineral sorbent

\section{The results of experimental research}

The absorbency tests of sorbents consisted of determining the percentage absorption capacity. Before starting the test, the mass of the dry sorbent was measured. Then, after absorbing the sorbent after 300, 600 and 900 seconds respectively, and the filtration, the mass of the soaked sorbent was measured. The next step was to calculate the mass of liquid absorbed by the sorbent according to formula (1). After the calculation, the percentage of sorbent $\mathrm{C}$ was determined according to formula (2). The results of calculations are included in Fig. 6 and 7.

$$
\begin{gathered}
m_{c}=m_{1}-m_{0}[\mathrm{~g}], \\
C=\frac{m_{1}-m_{0}}{m_{0}} \cdot 100 \%,
\end{gathered}
$$

where:

$m_{c}$ - absorbed mass,

$m_{0}$ - dry sorbent mass,

$m_{1}-$ moistened sorbent mass.

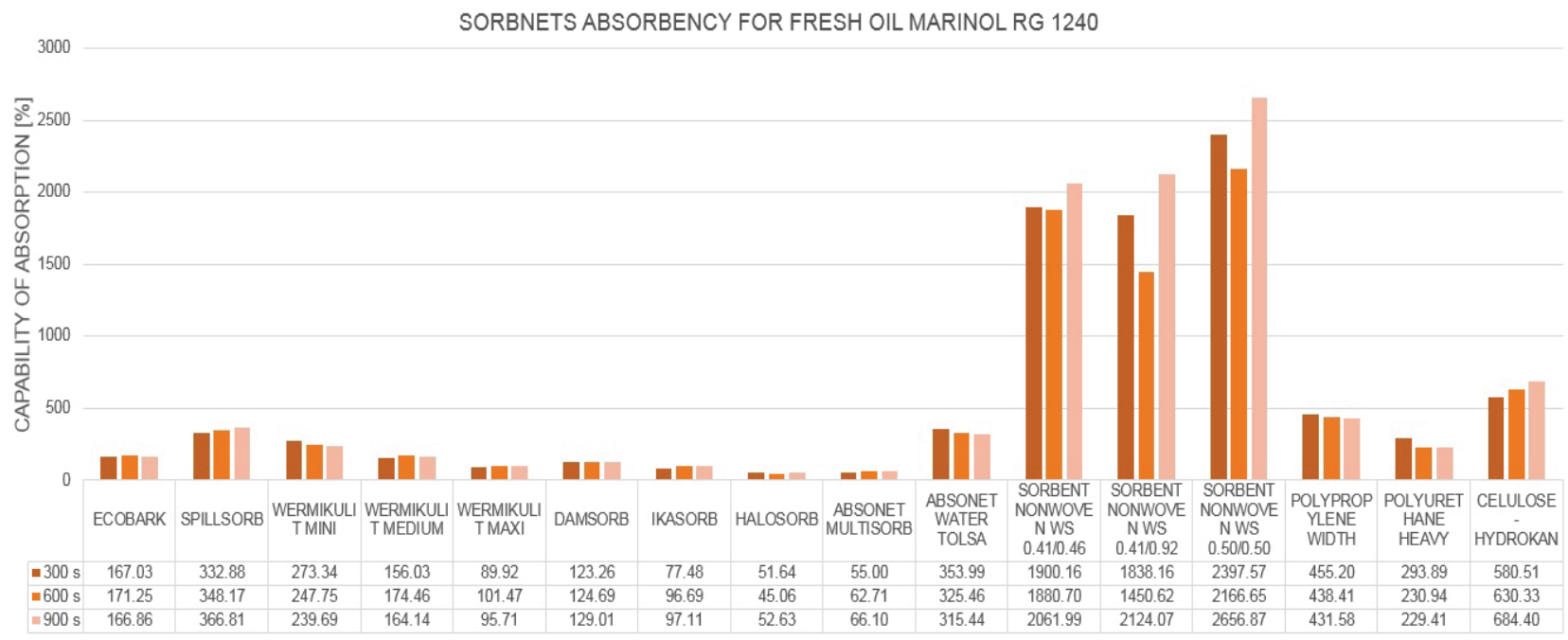

Fig. 6. Comparison of the absorptivity of the sorbents tested for fresh oil 


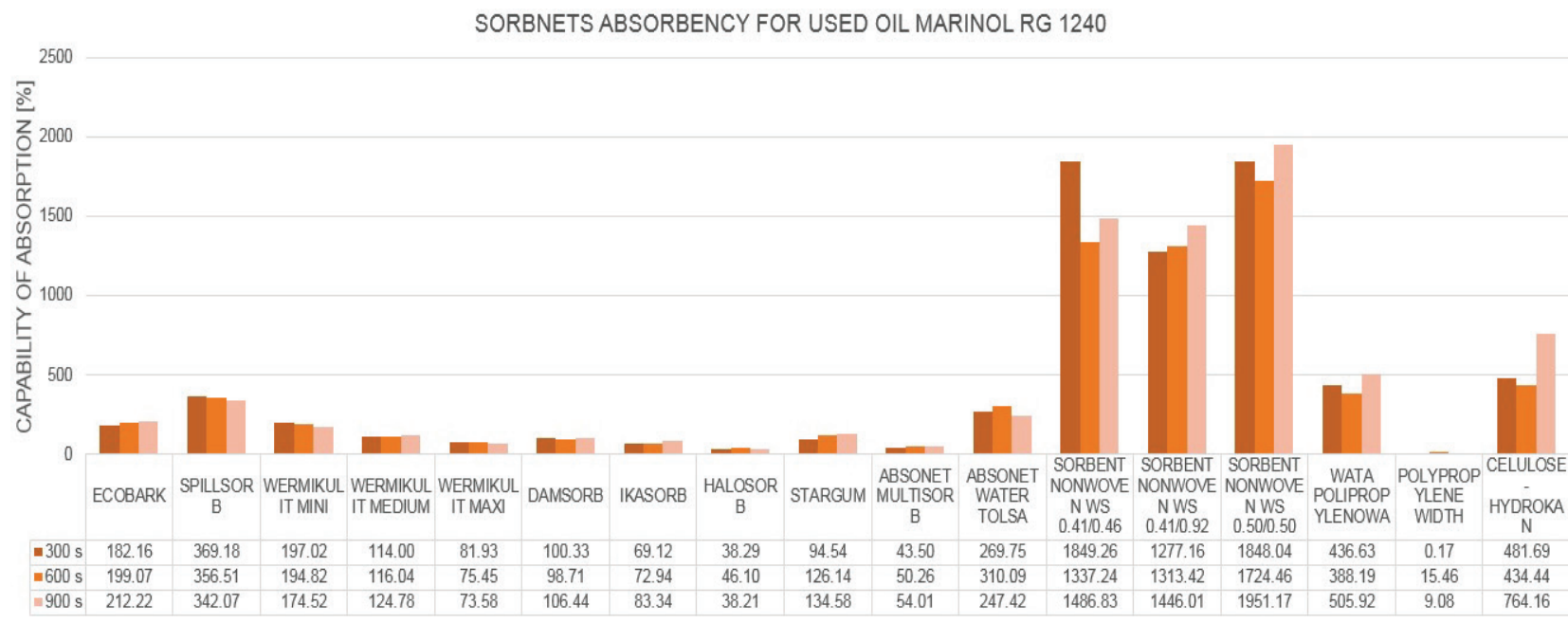

Fig. 7. Comparison of the absorptivity of the sorbents tested for used oil

\section{Summary and conclusions}

Sorbent tests were carried out for 2 different factors - fresh oil and used oil. From the group of natural sorbents the peaty sorbent Spill - Sorb is the best. The longer the absorption time, the greater the absorption capacity. This is due to the slow absorption of the substance, depending on the sorbent structure.

Absonet Water Tolsa was the most absorbent of mineral sorbents. It has a lot of air space in which the collected substance gets during the absorption. The highest absorption capacity shows with a short absorption time. From the group of synthetic sorbents, the highest absorbency was found in the WS 50 sorbent nonwoven $0.50 / 0.50$. Due to its construction and the way of laying the fibres, it is possible to absorb a very large amount of impurities.

For the used oil, the results show that the Spill - Sorb group was again more absorptive from the group of natural sorbents. The longer the absorption time, the greater the absorbency of the sorbent. This is due to the rapid absorption of material impurities in the used oil.

From the group of mineral sorbents, Absonet Water Tolsa proved to be the best one again. In the case of used oil, the highest absorption capacity was noticed after 600 seconds. It can be stated that impurities in used oil were absorbed together with liquid and after a certain time, impurities began to push oil out of the sorbent. WS50 Sorbent Nonwoven / 0.50 from the group of synthetic sorbents showed the highest absorbency.

Thanks to its construction, it has the ability to separate impurities contained in used oil. Tests of absorbency of water mixture with used oil have shown that natural and synthetic sorbents during the sorption process absorb water together with oily substance, and after some time the oil pushes out the collected water from the sorbent.

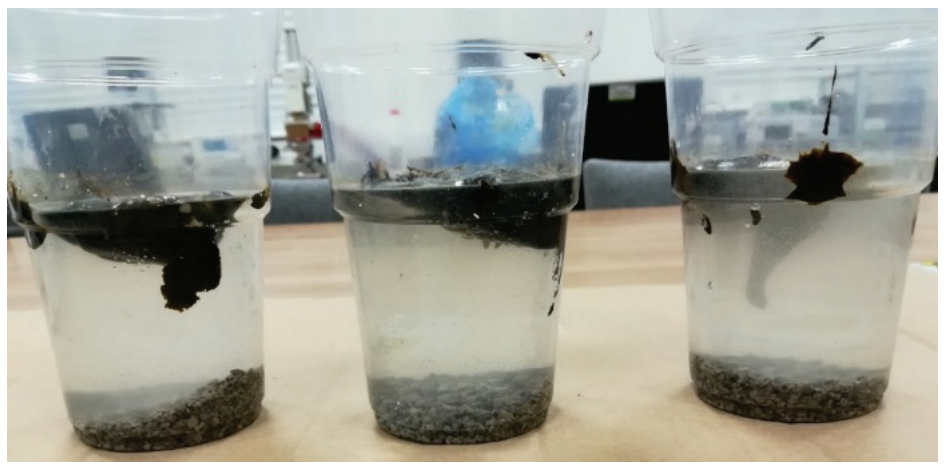

Fig. 8. Absonet Multisorb 
Another part of the absorbency tests was the performance of the test on the heavy fuel oil. Due to the density of $890-960 \mathrm{~kg} / \mathrm{m}^{3}$, there were problems with the preparation and removal of petroleum substances. The tested sorbent Absonet Multisorb received a negative result of the absorbency test, because it proved to be too heavy and instead of the sorption process, there was a fall on the bottom.

The research shows that the most absorbent means for removing oil and petroleum contaminants is the WS 50/0.50 sorbent nonwoven. Regardless of the tested environment and the type of pollution, sorbent nonwoven

WS $0.50 / 0.55$ far outperforms the sorption capacity analysed. Therefore, the nonwoven is the most suitable for combating pollution in port, coastal and hard-to-reach areas.

\section{References}

[1] Carmody, O., Frost, R., Xi, Y., Kokot, S., Surface characterization of selected sorbent materials for common hydrocarbon fuels, Surface Science, Vol. 601, pp. 2066-2076, 2007.

[2] Cooper, D., Gausemel, I., Oil spills sorbents: testing protocol and certification listing program, Proc. Thirteenth Biennial Conference on the Prevention, Behavior, Control, and Cleanup of Oil Spills, pp. 549-551, 1993.

[3] Cooper, D., Dumouchel, A., Brown, C., Multi-track sorbent boom and sweep testing, Proc. Twenty-eighth Arctic and Marine Oil Spill Program (AMOP) Technical Seminar, pp. 393-408, 2005.

[4] Kończewicz, W., Walaszkowska, N., Lachowicz, D., Otremba, Z., Laboratory study of effectiveness of sorbents intended for oil spill combating, Journal of KONES, Vol. 21, No. 4, 2014.

[5] Nowak, A., Environmental Security: Testing the absorbency of sorbents, Part 5, Gdańsk University od Technology, Faculty of Chemistry, 2011.

[6] Radetić, M. M., Jocić, D. M., Iovantić, P. M., Petrović, Z. L., Thomas, H. F., Recycled woolbased nonwoven material as an oil sorbent, Environmental Science \& Technology, Vol. 37 (5), pp. 1008-1012, 2003.

[7] Staniszewska, M., Bistram, K., Maritime transport as a source of environmental threats in the Polish maritime area, Journal of KONES Powertrain and Transport, Vol. 13, No. 3, pp. 362-363, 2007.

[8] Wei, Q. F., Mather, R. R., Fotheringham, A. F., Yang, R. D., Evaluation of nonwoven polypropylene oil sorbents in marine oil-spill recovery, Marine Pollution Bulletin, Vol. 46, Iss. 6, pp. 780-783, 2003.

Manuscript received 24 August 2019; approved for printing 20 December 2019 